\title{
School-University Collaboration Initiative: Benefits and Challenges in Uganda
}

\author{
Charles Opolot-Okurut ${ }^{1, *}$, Juliana Bbuye ${ }^{2}$ \\ ${ }^{1}$ Department of Science, Technical and Vocational Education, Makerere University, Kampala, Uganda \\ ${ }^{2}$ Department of Distance and Lifelong Learning, Makerere University, Kampala, Uganda \\ *Corresponding author: copolok@gmail.com
}

Received September 01, 2014; Revised September 16, 2014; Accepted September 24, 2014

\begin{abstract}
This investigation examined academic staff, school administrators and school teachers' perceptions of the university-school collaboration. A qualitative research paradigm was followed through a case study of Makerere University's use of Teacher Education in Sub-Saharan Africa-(TESSA) project materials. The case study focused on gaining a wealth of detailed information on a small sample of academic staff, school administrators, and school teachers while addressing the research questions of the study. Twelve participants were used for data collection from the university (three) and the primary schools (nine). Data were collected using semi-structured interviews organized around the key research questions. Results indicated that the gap between university academics and school teachers is narrowing. Some school teachers have changed their practices that appear to have improved their methods of delivery of content to the learners. The use of TESSA materials is altering teachers' teaching practices. But, the resources for university-school collaboration are varied and expensive. Teachers' workload appears to leave them little time to be effectively involved in collaborative activities. Conclusions from these findings were that there are both merits and constraints to university school partnership to the advantage of each institution; teachers are incorporating TESSA materials into their teaching practices. The implications of these findings for the universityschool partnership include the increased need for university and school administrators to support school teachers benefit from the collaboration; and to create more time for the involvement of all participating parties so that they can better implement the collaboration activities.
\end{abstract}

Keywords: collaboration, partnership, schools, teacher education, Uganda, university

Cite This Article: Charles Opolot-Okurut, and Juliana Bbuye, "School-University Collaboration Initiative: Benefits and Challenges in Uganda.” American Journal of Educational Research, vol. 2, no. 10 (2014): 843-849. doi: 10.12691/education-2-10-1.

\section{Introduction}

One universal question that teacher educators ponder across the world is 'how can universities and schools work together to address educational issues?' Traditionally, teacher education institutions and schools have lived separate isolated lives [1]. Yet, for improved student achievement, there is a quest for effective teacher preparation and continuous professional development of teachers across the world. Education departments in universities attempt to run programmes which are intended to develop high quality teachers needed in schools but they cannot do so singlehandedly. However, current thinking puts more emphasis on collaboration and partnership between universities and schools. Collaboration may be viewed as "processes through which parties who see different aspects of a problem can constructively explore their differences (and similarities) and search for solutions that go beyond their limited vision (capacity) of what is possible” ([2], p.5), which creates a new desired added value to participants individually and collectively.
Collaboration is "a process, and not an invent [sic]" that seems to work best provided a win-win interaction is established ([3], p.4), but it is often used synonymously with partnership. To describe university-school collaboration [3] uses the metaphor of a marriage involving comparability, attraction, respect and love, with concomitant problems, that also embraces unity in diversity. According to ([4], p.16) "partnerships are social practice achieved through and characterised by trust, mutuality and reciprocity [emphasis added] among preservice teachers, teachers and other school colleagues and teacher educators" that also include other stakeholders. Furthermore, for a partnership to hold, it must be formal and legally binding with clearly defined rules on power sharing, decision making, and so on, relative to a joint venture ([5]). Meanwhile, ([3], p.4) has argued that any successful "collaboration depends on leaders to communicate vision, build trust, manage conflicts, balance interests, and facilitate group interaction.” At the same time, the same author points out that potential origin of conflict in university-school collaboration emerge from "differences in activities, cultures, reward systems, schedules and goals” ([3], p.2), among other factors. 
Research reveals that several advantages and benefits exist in maintaining university-school collaboration as both the university and the schools gain mutual benefits from the interactions ([4,6,7]). University-school partnerships serve several purposes such as opening channels for sharing ideas and information, initiating, maintaining and upholding an open two-way communication system between the collaborating members.

For example, [8] cite Robinson and Darling-Hammond as having suggested 10 characteristics that are evident in effective university-school collaboration that include:

1) Mutual self-interest and common goals;

2) Mutual trust and respect (all parties recognize and utilize the talents and perspectives of each participant);

3) Shared decision making, from goal-setting to operations;

4) Clear focus (strong consensus regarding the outcome, a vision of the new organization to be created, and the mission of that organization);

5) Manageable agenda (mapping activities so that all are aware of how their efforts and the efforts of others contribute to the outcome);

6) Commitment from top leadership;

7) Fiscal support;

8) Long-term commitment;

9) Dynamic nature (members have the opportunity to revisit plans, incorporate new understandings and ideas, and change priorities as experiences dictate - having a map rather than an itinerary); and

10) Information sharing and communication.

Similar characteristics had earlier been identified by $([3,6])$ as critical processes, elements and characteristics that are necessary conditions for university-school collaboration. The list of characteristics was mainly based on field experiences of university students posted to schools in the university catchment area that included:

1) trust/responsibility;

2) time/commitment;

3) accountability;

4) mutuality/reciprocity;

5) choice/ownership/meaningfulness;

6) shared vision/beliefs;

7) flexibility/adaptability;

8) challenge/openness to growth;

9) respect; and

10) communication/sensitivity.

These characteristics are akin to each other and show that near similar issues are discussed in university-school partnerships at all levels.

In Australia, the university of Victoria research team [4] conducted a study, one of whose aims was to pinpoint exemplars of effective and sustainable university-school partnerships involving pre-service teacher preparation programme research, induction, and continuing professional learning for practicing teachers. Thus, the team [4] concluded that successful partnerships bring the stakeholders together around personalized and localized interests in learning, and school student learning particular.

\section{Context}

The benefits of conventional university-school partnerships are illustrated with reference to Makerere University,
Uganda, as a case. Makerere University got involved in the Teacher Education in Sub-Saharan Africa (TESSA) project in 2002. One type of partnership between university and schools is where students are sent to schools for school practice, or in the case of in-service students on projects within their own schools. University staff is sometimes invited as facilitators to school workshops and seminars or as supervisors of projects, and through partnerships, success factors in the collaboration can be identified and several barriers to the collaborations are sometimes encountered.

Currently, at Makerere University four avenues for university-school partnership are used, namely: 1) Students are sent to schools for school practice (practicum) or field attachment. 2) In-service teachers are sent on projects within schools in which they teach. 3) University staff act as either pre-arranged facilitators to school workshops and seminars or as supervisors of student projects. And 4) University staff assign in-service teachers work that links theory to practice to be done within their school environment. The collaborators in this partnership include: school administrators (head teachers) who are the principal link persons between schools and university; inservice school teachers are the key participants that practice the new approaches in schools; the university lecturers, especially from the College of Education and External Studies (CEES), are the instructors for the inservice student teachers at the University; and the university project coordinator is the key link person at the university who organizes the workshops in schools and generally monitors the project activities. Participating school teachers receive and use TESSA written (text module) materials; in Social Studies, Numeracy, Literacy, Science and Life skills. They are also provided with the CD-ROMs from the TESSA collection to refer to and to share with colleagues in their schools. The project coordinators from the university keep on checking with the tutors to identify progress and challenges. A limited number of staff is involved in this project and yet more colleagues should ideally be involved in the partnership for faster dissemination of the ideas and increase of the critical mass of personnel.

In general, research literature suggests that in teacher education effective teacher preparation can be enhanced through school-university partnership but there has been scanty critical enquiry into the processes involved to achieve genuine collaboration or how such processes affect learning. To address this lacuna of knowledge we examined the school-university partnership between a public university and primary schools in central Uganda. The purpose of the exploratory study reported in this article was to investigate participants' perceptions about the benefits and challenges in a quest for effective teacher preparation and continuous professional development of teachers in Uganda. Thus, the study probed the benefits and barriers to university-school collaboration. In particular the study sought answers to the following research questions:

Q1: What are the benefits of university-school partnership?

Q2: What are the challenges to university-school partnership?

Q3: How have you used TESSA materials in your institution? 


\section{Methodology}

\subsection{Design}

This study followed a case study research design [9]. To identify participants' perceptions a qualitative research paradigm was followed through a case study of Makerere University's use of TESSA-project materials that were initially developed at the Open University - UK and later adapted and versioned for the local context of African countries like Uganda that were involved in the project. The case study focuses on gaining a wealth of detailed information on a small sample of informants and sources, chosen specifically to address the research questions of the study [10]. The participants in this study were: (1) three primary school head teachers, (2) six primary school teachers (two from each primary school) and (3) three university academic staff members who were involved in the project willingly accepted to participate in the study.

\subsection{Instruments}

The researchers developed semi-structured interview guides, which were organized around the key research questions. Face-to-face interviews, with the 12 participants, were used for data collection based on [11] perspective. Semi-structured interviews were identified as suitable for exploration of perceptions and opinions of participants regarding complex issues. Furthermore, probing follow-up questions were utilized so as to clarify responses provided and to dig deeper into further information. There were three similar interview guides targeting the three categories of respondents; the university academic staff, school administrators and school teachers prepared, piloted, modified and then used for this study. The interview guides were also for gaining understanding of participants' perspectives on the university-school collaboration efforts being implemented. The interview guides had two sections: a section on biodata and the other on perceptions of the school-university collaboration. The second section consisted of 14 questions relevant to the research questions of the study. The interviewing sessions were held at a place free from distraction that was convenient to both the interviewer and the interviewee in the interviewee's institution. The interviews were audio recorded with permission from the interviewees, and field notes were also written by the interviewers. One interview was conducted with each of the participants. The authors and graduate student assistants conducted the individual interviews during the second term of the schools' academic year. Each researcher participated in half of the interviews conducted. The interviews focused on the participants' thoughts about their perceptions of the university-school collaboration and about their use of the TESSA materials for teaching.

Documentary analysis was also conducted on several materials that were being used in the schools and university but that data are not reported in this paper.

\subsection{Data Analysis}

The data for the analysis were the transcripts of the audiotaped individual interviews conducted with the 12 participants and accompanying the field notes. The process of data analysis involved several phases of coding.
We first separately transcribed the audiotaped individual interviews for the academic staff, school administrators and school teachers. The transcriptions enabled us to identify each respondent's comments on each of the questions in the interview guide. This analysis approach mirrors the qualitative data analysis process followed an interpretative lens $([9,12])$ relying on the constant comparative method $([11,12,13])$.

\section{Results and Discussion}

This study identified the barriers and benefits of university-school collaboration that could enhance preservice teacher development. In this analysis we present representative comments of the respondents to give a sense of the participants' language and descriptions of their perceptions of the university-school collaboration drawing attention to the similarities and differences of the responses. The organization of these data in this form is what [9] call 'organization by people' and according to 'issues' surrounding the questions guiding the research. Apparently the findings from the academic staff, school administrators and school teachers have more similarities than differences. Finally, we discuss the implications of the findings for the future of the university-school collaboration and future research. Thus, in this paper results of the initial data analysis are presented and discussed and suggestions made on how university-school partnership could be improved for the mutual benefit of the two entities for better teacher professional development. The first research question probed the benefits realized in the case study institutions to understand the impact of the university-school partnership. Q1: What are the benefits of university-school partnership?

Data collected for this part of the research involved interviews with academic staff, school administrators and school teachers in the case study institutions. The data was collected with the view to establish what participants perceived as the advantages of the university-school collaboration. The case study participants reported the most important benefits to the university and the schools. The findings are now described in more detail from the perspective of the academic staff, the school administrators and the school teachers.

One conspicuous finding is that there is a closer working relationship between the academic staff at the university and the teachers in the schools. One academic staff reported that "collaboration is bridging the gap between the university and schools" by bringing them closer to each other as they held joint educational activities. Another academic staff claimed that "the cordial relationships established with schools helps us at the university to learn more from them and promotes research into teaching at this level." Another benefit was that Bachelor of Education (B. Ed. external) programme tutors organize their teaching and learning using TESSA materials" when they meet the in-service teachers during the face-to-face sessions organized at the university campus. Thus promoting the child-centered teaching approach and activity based learning. The apparent closing gap between the academic staff and teachers in schools is due to the commitment and enthusiasm of the school administrators to involve their schools and teachers and 
the so far perceived and observed potential benefits of the collaboration. Another possible explanation is the ready availability of the TESSA materials that were supplied to the schools at no cost and the possibility of obtaining them from the World Wide Web (internet) as Open Educational Resources (OER). We are aware that an essential activity of teaching is the presentation of lessons. These findings support the characteristics of commitment, envisaged benefits and required resources that [4] have highlighted.

Another finding is that academic staff, and school teachers have changed their teaching and learners have altered their learning practices. For example, one school administrator pointed out that the collaboration "helps teachers to know how to handle their classes well" because they gained the knowledge to handle classes from presentations of university academics in workshops that were organized. Another school administrator pointed out that the partnership "helps children to learn how to use materials around them in the learning situation and to take a leading hand in their own learning," which was advocated for by the use of TESSA materials. The university-school collaboration introduces friendship: thus bridging the gap between the university and schools and enhances the cordial relationships established with schools that help the university to learn more from the schools, and to promote research into teaching at this level. It is possible that the use of TESSA materials was catalyzed by the program requirements for the participants. Also, there may be extraneous factors not examined in this study that influence teachers use of the TESSA materials apart from their need to successfully complete their degree programs, because they were registered university students. These findings support [6] result that the education of teacher candidates was enhanced through university-school collaboration.

One school teacher declared that "the university-school collaboration has made it possible for me to watch other teachers teach and pick what is best from them and use these ideas to improve my class and with time I have learnt to carefully observe my own learning environment."

Furthermore, the teacher observes that through collaboration other teachers have been able to watch him teach and make their observations about what and how he teaches. For example, he was able to make the children discover for themselves the concept of fractions by using realia (apples and oranges) to get the desired portion of a whole when he taught fractions; thus providing an active role in their own learning.

After the observations were made we would then collaboratively have a debriefing and share ideas. I can say that using the child-centered approach to improve the quality of learning, which I believe is the goal of this collaboration, has made it possible for us to effectively use the local environment to make the children understand better. Everything in our environment is at our disposal for teaching so long as we can creatively use them to make our pupils learn better.

These findings are possibly encouraged by the emphasis on collaborative, cooperative and group work that is advocated for in teachers training as an approach to active teaching and learning strategy. The use of group work, despite the large class sizes, is strongly encouraged both in the university and the schools. One possible explanation for the result is that the debriefing after lesson presentation with colleagues is a healthy educational practice among colleagues. This finding agrees with [6] advocacy for all parties involved in a collaborative relationship to be trustworthy and responsible.

Some of the school teachers have consulted and embraced the use of TESSA materials and shared experiences with colleagues in the school. For example, one teacher participant alluded to the fact that:

I have watched the CD-ROMs on TESSA materials and learnt a great deal and this has made me change my methods of teaching. I can confidently say I do teach better now. I am also able to advise my colleagues on the best way to teach to make the children pick easily the subjects and topics they are teaching.

Referring to personal experience the same respondent continued to say that:

This means for me that this practice is contributing to team teaching and team learning in my class which is beneficial to all involved. My friends learn from me and I also learn from them and we learn from our pupils. I can say this collaboration has been an active learning process for me.

Yet another school teacher participant identified a major limitation of the nature of some of the existing teacher candidates as hardly being able to communicate well both in spoken and written English. The teacher believes that if collaboration works well, in the long run, the university will begin to admit students who are confident, articulate and self-driven in their learning, than is currently the practice. The participant further continued that I also envisage that "this collaboration can help promote more research in universities especially school based research.” It provides learning opportunities for both the teachers and the children. It makes us able to teach better and pupils learn better by becoming more actively involved in their own learning. Furthermore, it adds to the popularity of our school being one of the few schools whose teachers have been trained to use the TESSA materials which advocate for child-centered approach to teaching in schools. This collaboration opens up opportunity for Makerere University to collaborate more with schools as well as with other universities to improve the quality of learning in schools. However, because some of our lecturers are already using the learner-centered approach to teach students, the participant believes that when TESSA materials are used well and understood by students, the university students who are training to become teachers would then translate the same approaches in schools they teach to improve the quality of learning in lower levels of learning thus generating a ripple effect.

In general, these findings suggest strong usefulness of the university-school collaboration to the benefit of the staff of the university and schools. However, the collaboration must be built on a firm foundation embedded on trust, mutuality and reciprocity [4]. The benefits of the collaboration for the school teachers to grow professionally in their practices are evident. Thus the training of teachers cannot happen in the university alone; it must be a shared effort with the schools where the teachers are attached to for their school practice, and where they will eventually be employed. The university and schools are also able to share resources and be able to conduct joint research. It is worthy to take a leaf from 
([14], p.59) who quite rightly argue that "collaboration will only be successful when institutional 'core' values and purposes can be reconciled whilst all the partners contribute their distinctive skills," knowledge and expertise.

Q2: What are the challenges to university-school partnership?

The second research question examined the challenges faced by staff in the case study institutions in order to diagnose the impact of the university-school partnership. There were hardly any challenges identified by the academic staff and the school administrators indicting that they were satisfied with the status quo and busy with the logistics of the activities to pay attention to other issues. The only issue raised was that the minimum exposure of academic staff to TESSA materials and their low use. This could be because the TESSA materials are targeted at primary school learners and could be considered below the university curriculum level. The challenges were therefore mainly identified by the school teachers. Meanwhile, the university academic staff pointed out that there was a lack of TESSA desk for consultations in the colleges at the university.

School Teachers. One expected finding was that the school teachers identified lack of adequate resources to run the necessary collaborative activities as a major challenge of the collaboration. In the words and voice of one of the school teachers "funding of workshops and other activities are not well facilitated," which indicates minimum administrative support. And yet, another school teacher explained "for urban schools some materials may be hard to come by; some of the materials are expensive to get and lack of adequate space for the large numbers of learners and teachers to use activity-based teaching and learning." A possible explanation of this finding is the huge number of pupils (in excess of 60 in one class) in primary schools that makes it more difficult to have adequate quantities of learning materials together with government policies surrounding the Universal Primary Education program that has low funding for school activities. These findings echo [7], p.1044) who identified resources as fundamental in the university-school collaboration saying "adequate funds and resources should be provided to establish and to sustain the activities associated with collaboration.”

Another identified common challenge is the time to fit collaboration activities into the busy workload of the school teachers. This engagement suggests that the monitoring of the project to check on the teachers may be problematic if not well planned, and the time to run workshops if not availed may lead to problems. Lack of time on the part of the teachers could be because of understaffing and inadequate number of teachers in schools leading to heavy teaching loads in the schools. The same teachers are also involved in school cocurricular activities and other school administrative responsibilities. This finding agrees with the findings of [7] who indicate that among the conditions necessary for successful school-university collaboration is time commitment on the part of the partners. In other words, how available are the partners for the planned activities of the collaboration? Time needs to be opened up for effective partners' collaboration.
These findings also reveal obstacles of and barriers to university-school collaboration that hinder growth of the institutions and their physical and human resource. However, the collaboration must be built on a firm foundation embedded in trust, mutuality and reciprocity [4]. The glaring benefits of the collaboration for the school teachers to grow professionally in their practices are unmistakable.

In general, these findings reveal the road blocks to the university-school collaboration that may hamper harmonious working between academic staff and school teachers. Successful collaboration is built on coordinators and leaders who communicate vision, build trust, manage conflicts, balance interests, and facilitate group interactions [15].

Q3: How have you used TESSA materials in your institution?

The third research question probed how the TESSA materials were used in the case study institutions to comprehend the impact of the university-school partnership.

School administrators. The TESSA materials were distributed to the pilot schools and the school administrators acknowledged receiving them, they utilized them for learner-centered teaching approaches while using realia and local materials. One school administrator's positive observation was expressed as follows.

We have received and used the written materials; we have also watched the CD-ROMs from the TESSA collection. These TESSA materials have helped teacher to apply child-centered ways of teaching effectively. Whatever they teach they make sure that they use the local material on the environment to make learners understand better and make sure each learner is actively participating. They also teach outdoors where they enable learners see and use what is in the local environment.

An explanation for this result is partly because of the easy access to the TESSA materials, which were supplied, eliminated the need for funds from the school to purchase those materials. This lifted a heavy burden from the school administrators whose financial budgets are rather dismal.

School teachers. School teachers indicated that some of them have picked ways of engaging learners both in the classroom and outside the classroom and also involved the parents and local materials in the learning process. For example, one school teacher reported.

I have used the TESSA materials very fruitfully and my pupils have benefitted a lot from our use of these materials as a teaching resource. I mainly take my class outside the classroom and make them learn using materials from the natural environment within the school. I also get materials that are brought by parents especially when the children celebrate their birthdays as I said earlier. I keep what I know can be of use for learning for example straws and bottle tops.

Another teacher reported having picked the teaching approach that is learner-centered and active learning through group work as advocated for in the TESSA materials in the following statement.

I ensure the children learn mainly in groups. So I divide them into groups, we identify the group chairperson, secretary and presenter and this keeps rotating. So I give a task form the TESSA materials and the pupils 
work on their tasks and report to the class at a later stage. This activity keeps them very busy and they also learn to take on responsibilities and to volunteer to take leadership roles.

Another school teacher was quite positive and supportive of the introduction of the TESSA materials in the school saying, "I have used the TESSA materials very successfully with my pupils for teaching English language. For instance, I have used the approach for teaching new words and to engage pupils in differentiating between words and meanings. In their groups children made balls and ropes out of banana fibers, which they got from the plantation in the locality..." The children were also able to make comparisons of weights and lengths of items. They were also able to conduct hands-on activities using local materials. These activities were seen to excite pupils who, as a result, wanted to go on and on with the activity. The participant concludes that I believe these activities make the learners more active and creative.

In sum, these findings suggest that the pilot schools have embraced the use of the TESSA materials which were availed through the university-school collaboration. However, the collaboration must be built on a firm foundation embedded in triad of trust, mutuality and reciprocity [4].

\section{Conclusions and Implications}

The purpose of this study was to investigate participants' perceptions about the benefits of universityschool partnerships; and identify barriers of such partnerships in order to try to improve pre-service teacher preparation and in-service continuous professional development of teachers in Uganda. Before drawing conclusions for this study the reader is drawn to some of its limitations. First, the small number of participants from primary schools; it is quite feasible that respondents' comments were influenced, at least initially, by the researchers' presence and emphasis during the interviews by the categories of differences of respondents. Consequently, we cannot generalize these findings to all forms of school-university collaboration. Second, this study concentrated on the academic staff, school administrators and school teachers but did not investigate the impact of the collaboration and TESSA materials on school students' attitudes and achievement, which are key indicators of student progress in the learning process. It is apparent that it is hard to adequately determine the accomplishment of any program without evidence of student achievement. Third, this small qualitative study only used interviewing to collect data. The use of quantitative self-report questionnaires could have helped to triangulate the data. In addition, if mixed methods were used, richer data could probably have resulted. However, in spite of these limitations we believe that there are significant points to learn from the respondents' perspective in the analysis.

These research findings provide insight into the perceptions of the academic staff, school administrators and school teachers with respect to the impact of the university-school collaboration in university and school context.
In this study we considered Makerere University collaboration with primary schools using TESSA materials as a case study. Our aim was not to generalize the findings to other forms of school-university collaboration. However, the lessons learnt from this study show that primary schools have interest in working collaboratively with institutions of higher learning.

Data analysis from this research study and a closer look at the interview transcripts enabled us to draw the following conclusions and offer direction for future research. First, school-university collaboration enhances closer working relationship between institutions; enable teachers to practice new ways of working; enhance teachers' professional development and has potential to improve teacher preparation programmes. Both institutions have potential mutual benefits in one way or another.

Second, there was lack of adequate finances to acquire adequate resources and the lack of space for the large number of students. Furthermore, lack of flexibility and commitment of time for the activities of the schooluniversity collaboration for school teachers who already have heavy teaching loads coupled with other school administrative responsibilities is evident. Meanwhile, at the university level academic staff are also overloaded though, in addition, they are still expected to perform the key functions of their roles of teaching, research and providing community service.

Third, the ready availability of the TESSA materials including the OERs in the internet for use by school teachers and the university academic staff encourages teachers to use those materials in their teaching, thus lifting the burden of looking for money to purchase teaching resources for the specific areas of the curriculum.

This study has addressed a grey area of research in Uganda. It has exposed some of the advantages and difficulties encountered in the university-school collaboration initiative; and it has contributed to new knowledge on university-school relationship that could be incorporated into pre-service teacher preparation programmes and into the in-service teacher continuous professional development programmes. The findings from this research attract further research and invites researchers to this virgin area of research. Furthermore, implications for this study include: First, there is need for teacher educators to recognize the importance of building relationship with colleagues and with teachers in schools. Second, the areas of university-school collaboration need to be diversified to include mentoring and staff development programmes. Third, there is need to review both pre-service and in-service teacher education programmes to incorporate tighter, closer and supportive working together between staff of the collaborating institutions.

In total, future research is needed to clarify the impact of the university-school collaboration on the pre-service teacher preparation and also in-service teacher professional development and how that may impact on the university education programmes for teacher preparation. The need for a whole-school approach to enhance teachers' continuous professional development is evident and necessary for consideration. However, more questions among others remain unanswered such as: has universityschool collaboration improved the education of preservice teachers? Has the child-centered approach 
impacted on students' motivation, school attendance and dropout rates?

\section{Acknowledgement}

The authors would like to thank the academic staff, school administrators, and school teachers for their willing participation in the study. We also acknowledge the involvement of our graduate assistants in data collection. We thank the editor and the anonymous reviewers for the helpful comments and suggestions in improving the quality of this article.

\section{Statement of Competing Interests}

The authors have no competing interests.

\section{List of Abbreviations}

CD-ROM - Compact Disc - Read Only Memory CEES - College of Education and External Studies OER - Open Educational Resources TESSA - Teacher Education in Sub-Saharan Africa UK - United Kingdom

\section{References}

[1] Broadbent, C. and Brady, J., Leading change in teacher education in Australia through university-school partnerships. The European Journal of Social \& Behavioural Sciences (eISSN: 2301-2218). 687-703. 2013.

[2] Gray, B., Collaborating: Finding common ground for multiparty problems, Jossey-Bass, London, 1998.
[3] Clarken, R. H. University/school collaboration: A case study. Paper presented at the annual meeting of the American Association of Colleges for Teacher Education, Washington, DC, 1999.

[4] Kruger, T., Davies, A., Eckersley, B., Newell, F. and Cherednichenko, B., Effective and sustainable university-school partnerships: Beyond determined efforts by inspired individuals, Victoria University, Canberra, 2009.

[5] Arsenault, J., Forging nonprofit alliances, Jossey-Bass, San Francisco, 1998.

[6] Clarken, R. H. Toward more effective education through university and school collaboration. A paper presented at the annual meeting of the American Educational Research Association, Seattle, WA, 2001.

[7] Wasonga, C. O., Rari, B. O. and Wanzare, Z. O. (2011). Rethinking school-university collaboration: Agenda for the $21^{\text {st }}$ century. Educational Research and Reviews, 6(22). 1036-1045. 2011

[8] Whyte, A. and Ellis, N., The power of a network organization: A model for school-university collaboration. Contemporary Issues in Technology and Teacher Education, 4(2). 137-151. 2004.

[9] Cohen, L., Manion, L. and Marrison, K., Research methods in education, (6 ${ }^{\text {th }}$ edn.). Taylor \& Francis, London, 2007. [E-Book] Available netLibrary e-Library.

[10] Patton, M.Q., Qualitative research and evaluation methods, ( $3^{\text {rd }}$ edn.), Sage, Thousand Oaks, CA, 2002.

[11] Merriam, S. B., Qualitative research and case study applications in education, Jossey-Bass, San Francisco, 1998.

[12] Strauss, A. and Corbin, J. Basics of qualitative research: Grounded theory procedures and techniques, Sage, Newbury Park, 1990.

[13] Miles, M. B. and Huberman, A. M. Data management and analysis methods. In N. K. Denzin, and Y. S. Lincoln (Eds.), Handbook of Qualitative Research, Sage, Thousand Oaks, 428-444, 1994.

[14] Martin, J., Tett, L. and Kay, H., Developing collaborative partnerships: Limits and possibilities for schools, parents, and community education. International Studies in Sociology of education, 9(1). 59-75. 1999.

[15] Konecki, L. PDS professor/coordinators and their practices: Beliefs emerging from critical incidents journaling. Presentation at the annual meeting of the American Educational Research Association, San Diego, CA. 1998, April. 